\title{
Design of the turbocharger bearing arrangement to increase the overall efficiency of the combustion engine
}

ARTICLE INFO

Received: 27 July 2021

Revised: 16 September 2021

Accepted: 16 September 2021

Available online: 20 September 2021
The main objective of this study was to design a journal bearing, such that it can withstand the forces that arise in context to increasing the length of the shaft in an automotive turbocharger. The work will also provide information on how the design changes affect the overall performance of the bearing. The design changes include the thickness of the oil film, the number of grooves, the dimension of the grooves, the number of inlets and outlets, the dimension of the babbitt and mainly the length of the journal bearing. The simulation models were created using CATIA V5 and the analysis is done using ANSYS 19.2. The flow is considered to be laminar and is calculated using Reynold's Equation. The new concept gave insight on how the design considerations affect the pressure distribution and the pressure developed. From the results, it was interpreted that the new design can withstand the four times the pressure while distributing the pressure over twice the original design.

Key words: turbocharger, journal bearing, design, simulation

This is an open access article under the CC BY license (http://creativecommons.org/licenses/BY/4.0/)

\section{Introduction}

The development of internal combustion engine has led to the discovery of new components which improve not only the power but the emission also. The thirst for power paved the way for the construction of turbochargers. Turbocharging has now become a very popular way of increasing the power output of internal combustion engines. This simple and compact piece of machinery is typically imparting a boost of 0.4 to 0.6 bar.

The turbocharger became popular due to fact they are light weight power packs, which not only improve the power but the emissions as well. But the turbocharger on its own is not that efficient. To increase the efficiency, intercoolers were provided to improve the density of air that is compressed using the turbocharger. The high operating temperature of a turbocharger causes the air to expand after compression [20]. The level of expansion determines the size of the intercoolers required. The increase in the temperature of the inlet gases, also increases the $\mathrm{NO}_{\mathrm{x}}$ emissions due to peak in-cylinder temperatures [12]. The longer length of the exhaust system also tends to increase the pressure loss in the system. The longer exhaust system also increases the turbo-lag which is a primary concern in turbocharging.

The turbochargers are considered to be very inefficient at low speeds, which increases the turbo-lag. There is also a heat transfer from the turbine to the bearings, which causes damages due change in mechanical properties of the bearings $[5,15]$. The oil properties are also varied extensively since it has been proved that the oil takes out about $30 \%$ of heat from the turbines $[8,20]$. The insulation of the turbine is a solution which has been widely used to decrease the heat transfer between turbocharger components [18].

A solution to some of these problems were found out by Mercedes in the Formula-1 endeavours, as they introduced the first split turbocharger engine. The splitting of the turbine (hot) and the cold (compressor) side was done to reduce the heat interactions of the high temperate gases from the exhaust to the inlet air. This in turn helps in decreasing the exhaust system length. The split turbocharger system contains a longer shaft which increases the separation between the hot and cold side. The shaft is supported by a special bearing system, which sustains the load of the shaft which rotates by 50,000-250,000 rpm. The longer shaft also has given a possibility of introducing a special energy recovery system called MGU-H (Motor Generation Unit-Heat).

\section{Turbocharger bearing systems}

The arrangement of the bearings is based on where the turbocharger is installed and used. The regularly used arrangement of the bearings are in between the turbines as shown in Fig. 1A. This configuration makes it easier to supply oil, since all the housings are separated. The bearing access is provided by removing the turbine housing. The (B - Fig. 1) configuration decreases the need for a long shaft, thus decreases vibration and forces produced by the shaft. But the configuration also increases the problem of introducing a more complex lubrication system. The layout of the bearing system $(\mathrm{C}-$ Fig. 1) causes a large heat transfer between the turbines, which decreases the density of the compressed air $[2,14]$.

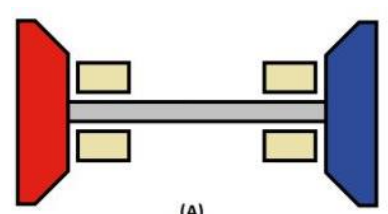

(A)

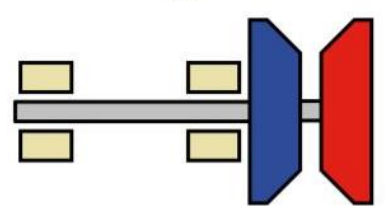

(C)

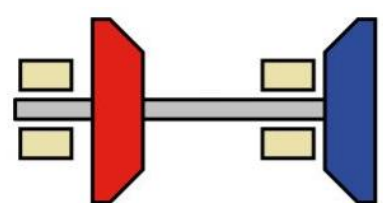

(B)

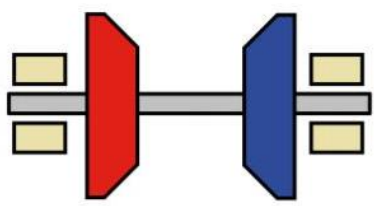

(D)
Fig. 1. The different bearing arrangements in a turbocharger [19] 
The advantage of this configuration is the separation of the gases system and the lubrication system. The turbochargers used in marine or large-scale application uses the (D - Fig. 1) configuration. This configuration enables easy maintenance options, but the bearing capacity at high speeds are decreased.

\section{Research methodology}

This publication presents the results of design works of new slide bearing solutions. The research methodology was based on the characteristics of the oil film which, through the required pressure, can support the shaft. The starting point was standard bearing journal designs from one of the automotive turbochargers. The design changes included the thickness of the oil film, the number of grooves, the dimension of the grooves, the number of inlets and outlets, the dimension of the babbitt and mainly the length of the journal bearing.

The simulation models were created using CATIA V5 and the analysis is done using ANSYS 19.2 - education version [1]. The flow was considered to be laminar and was calculated using Reynold's Equation.

The journal bearings were designed to support the longer shaft, with pressures exceeding the twice the existing condition. The design concepts focused on decreasing the efficiency losses by improving rotor dynamic stability and pressure distribution [10, 24]. The journal bearings were designed in two parts, journal and the steel backing. Each of the parts were designed individually and were analyzed to understand more about how the parts work separately. The forces acting on the oil film were only radial forces. The same radial forces were administered on the face of the babbitt and the steel backing of journal bearing. The frictional forces or the axial forces were not considered here, since axial forces were supported by the thrust bearing and absence of the shaft nullifies the frictional force.

The bearing analysis was only considered for the inner oil film and whether the new design can sustain the pressure of oil film, even though the journal bearing used for the analysis is a fully floating bearing. The data which was experimentally found was used to estimate the pressure output of the oil film. The assumptions which were taken are as follows:

- the flow was considered to isoviscous [22],

- the pressure was taken as ambient,

- the outlet pressure was considered as zero,

- no external heat was added to the system,

- the property of the oil remained the same throughout the analysis,

- the oil was considered isotropic and incompressible [16].

The babbitt was designed such that the clearance between the babbitt and the shaft should produce the desired oil film. The babbitt was developed in 2 different dimensions, this was to test how the thickness of the babbitt influence the factor of design safety and deformations.

The final piece of the puzzle was the steel backing of the journal bearing. The dimension of this was decided by the thickness of the babbitt used. The steel backing was taken the shape of the outer surface of the babbitt to complement the stress distribution. Together with the babbitt and the steel backing, the whole design of journal bearing which produced the required oil film was completed.

The assumptions taken while using the methodology were, no lubricant flows in the axial direction, there is no eccentricity between the shaft and the bearing, and the oil film cannot support the load acting on it.

The research temperature ranges have been adopted from other publications $[6,13,21]$ and were ranging from $310 \mathrm{~K}$ to $350 \mathrm{~K}$. The viscosity of lubrication oil is termed to be a non-linear function in the range of 310-370 K [6]. In paper [21] states that the bearing temperature ranges from $290 \mathrm{~K}$ to $290 \mathrm{~K}$ during operation. Thus, it was assuming the case of $370 \mathrm{~K}$ as inlet temperature to avert any problems that may occur in the future. The inlet pressure was set $0.101325 \mathrm{MPa}$ and velocity was $12.5 \mathrm{~m} / \mathrm{s}$ during the initial setup [13]. The pressure under operating conditions reaches up to be $4.0 \mathrm{MPa}$ at $60,000 \mathrm{rpm}$ (based on the load acting). To support an excess load and excess pressure created, the journal bearings are to be designed for 12.0 MPa pressure and for a rpm of 200,000 to 250,000 . Because it was very hard to have an overall good pressure distribution, the worst-case scenario was taken [17]. The oil is taken to have a density of $889 \mathrm{~kg} / \mathrm{m}^{3}$ and a dynamic viscosity of 1.06 $\mathrm{kg} / \mathrm{ms}$. This is the engine oil configuration used in ANSYS system. The specific heat of the oil is taken as $1845 \mathrm{~J} / \mathrm{kgK}$ and the thermal conductivity is taken as 0.145 based on the literature [2, 21].

\section{Model designing}

The considered designs of oil films were introduced after different analysis which provided how the changes affect the pressure distribution. The one inlet design (Fig. 2) helps in reducing the complexity in production. This first design was simple, using one inlet around the circumference and using the periphery as the only outlets. Since the size of the outlet is small, the restriction for the flow was more hence the pressure increases significantly [3].

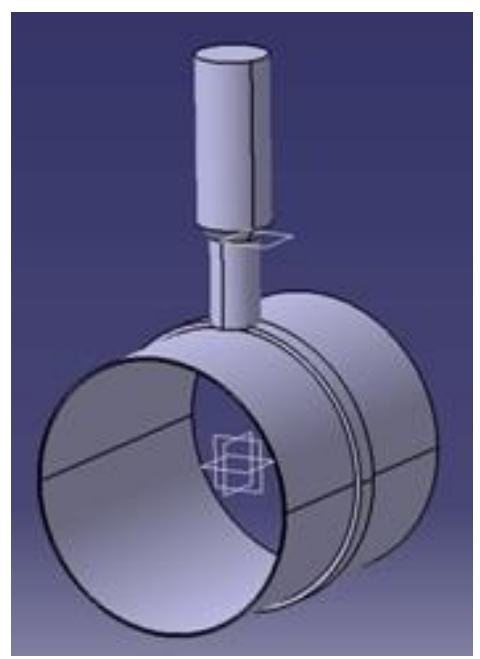

Fig. 2. Design of the oil film 1

The second model (Fig. 3) consists of 2 inlets and 2 outlets opposite to each other with a groove connecting them to regulate the flow of oil. The thickness of the oil film was reduced to by $25 \%$. 


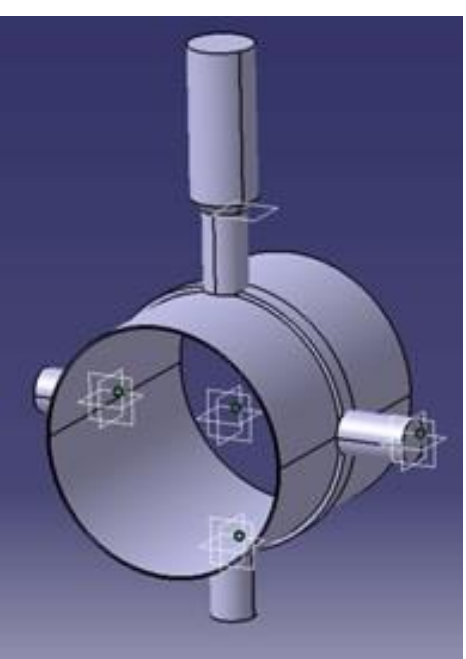

Fig. 3. Design of the oil film 2

The third oil film model (Fig. 4) consisted of 3 grooves instead of one, which was a design progression which was led by the previous analyses. The length of bearing was also increased from $12 \mathrm{~mm}$ to $20 \mathrm{~mm}$.

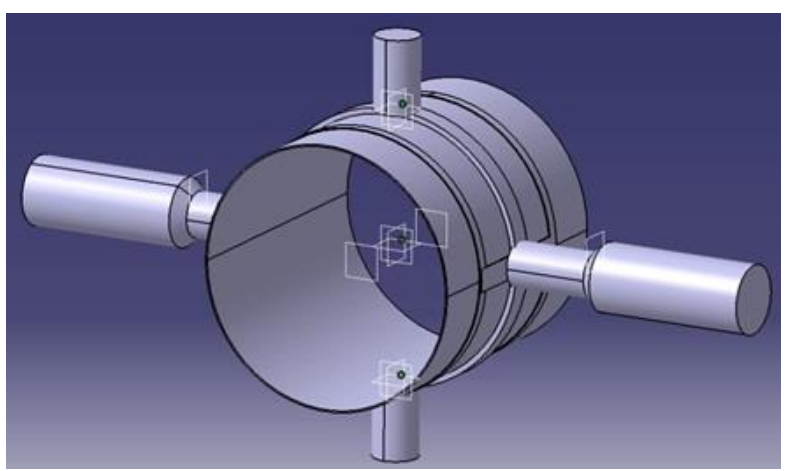

Fig. 4. Design of the oil film 3

The final design (Fig. 5) consists of 4 inlets and two outlets which are place perpendicular to each other. To incorporate the changes in pressure distribution due to increase in length, the inlets and outlets were modified.

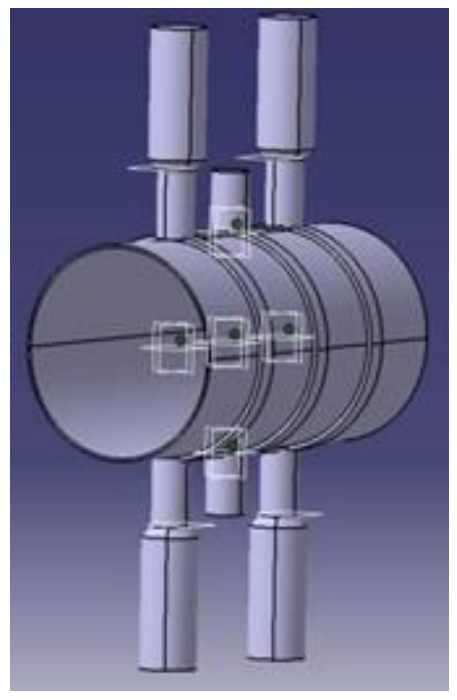

Fig. 5. Design of the oil film 4
The journal bearing (Fig. 6) was designed in according to last mentioned oil film design. The overlay is made in three thicknesses to check whether which thickness is suitable for the pressure distribution and oil flow. The three thicknesses where selected based on the data obtained on the commonly used thickness for the material. They are 100 $\mu \mathrm{m}, 50 \mu \mathrm{m}, 35 \mu \mathrm{m}$ and according to the thickness of the overlay, the thickness of the backing changes to reach the chosen diameter [23].

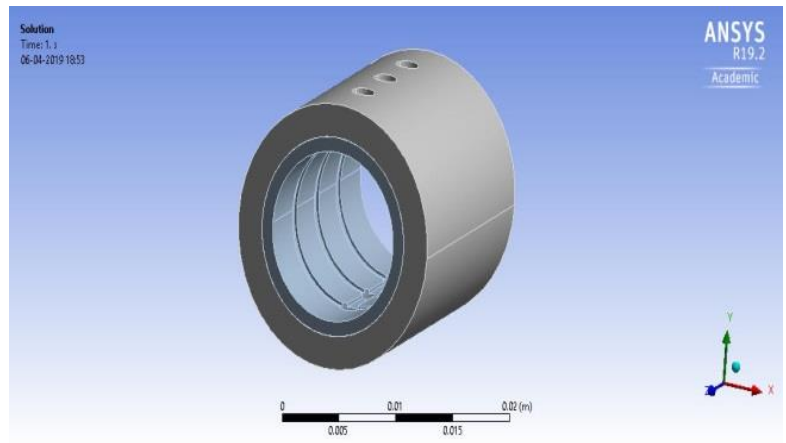

Fig. 6. Design of the bearing $1(1 \mathrm{~mm})$

\section{Data and results analysis}

\subsection{Computation}

The simulation was done using the CFD/FEM software ANSYS. The available version was an education version which had several limitations in analysis. The maximum number of the nodes which were usable in the design was $512 \mathrm{k}$ nodes. The maximum number of faces that the model can have is 300 and the number of bodies was limited to 8 .

\subsection{Model meshing}

The analysis for the oil film is done using the fluent analyser module of ANSYS 19.2. The element size was selected to $0.0007 \mathrm{~mm}$ for the accuracy. The mesh growth rate was program controlled. The model was set as solid structure with the material as babbitt. The babbitt was given boundary conditions, the ends are constrained in $\mathrm{x}, \mathrm{y}, \mathrm{z}$ axis for zero movements. The pressure was imported from the oil film analysis and is applied on the selected faces of the babbitt.

The number of nodes were 18609 and the elements were to be 8933 . The whole journal bearing model with the steel backing was imported and meshed. The pressure is imported and is applied to the inside faces of the babbitt. The boundary condition remains same for the babbitt and the steel backing. The analysis is repeated for all the models of the babbitt.

\subsection{Materials}

The most sound operation of a journal bearing is obtained when the material used to make the bearing combine both high strength with softness $[9,11]$. This in a little paradoxical but most of the bearing materials have the combination of these properties with a little compromise on their side. There were three components which required materials to consideration during the analysis, like the two parts of the journal bearing and the oil film. The overlay is a smooth material which can produce less wear and tear if there is any contact with the journal, the backing is usually a hard material which can absorb the load and withstand it for a long time. 
The oil is taken as the lubricant for the operation. The materials which comes into contact with shaft was made of a metal matrix composite called babbitt $[4,7]$. The material which is backing the babbitt was selected from three optional steels which are available in the market. The steels which were selected are AISI 1018, 1020, 1022, in which the AISI 1020 provided the required mechanical properties.

\subsection{Oil film analysis}

When considering the analysis of the first design, the oil film was having the highest pressure near to the inlet and was decreasing at a rapid rate while moving away from it. The groove has allowed the oil to produce some pressure at the bottom of the film. But it can be observed (Fig. 7) that the pressure is too high, reaching up to $50.0 \mathrm{MPa}$. This means there should be a change in velocity to decrease the pressure formed.
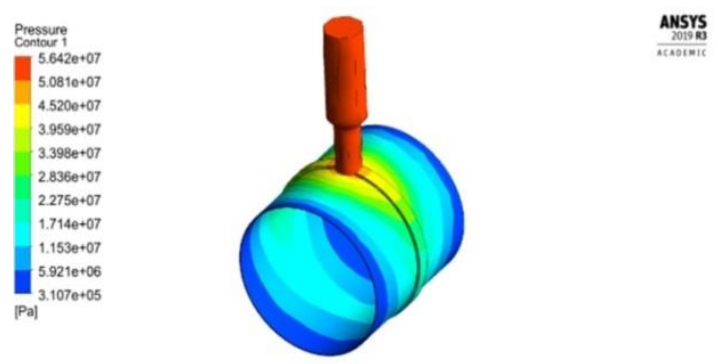

Fig. 7. Pressure distribution inside oil film 1

By introducing a second inlet parallelly opposite to the first one (Fig. 8), increase in the flow to all the circumference of the oil film. The overall bearing capacity was increased and there is less pressure losses in the film.
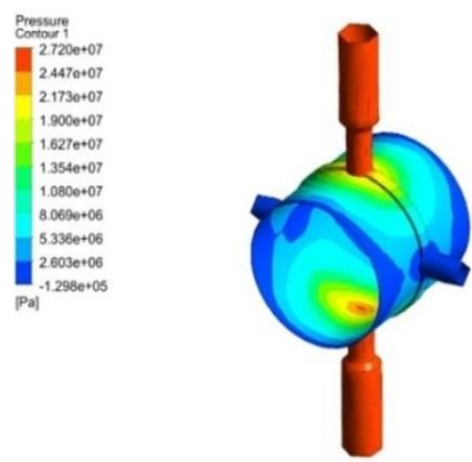

ANSYS

Fig. 8. Pressure distribution inside oil film 2
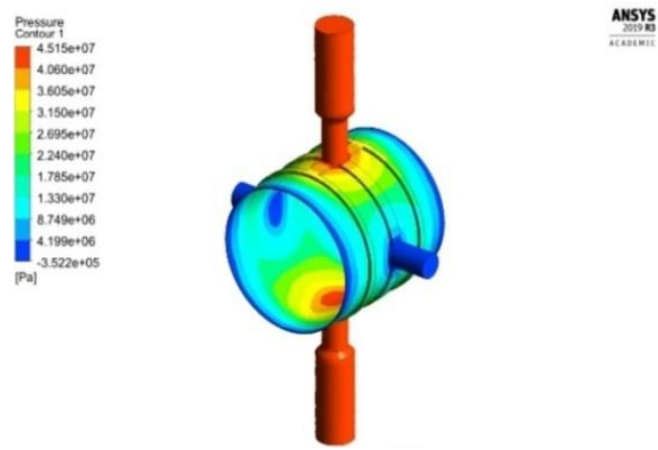

Fig. 9. Pressure distribution inside oil film 3
Next oil film had 3 grooves to flow which was used to transfer the oil to the extreme ends of the film (Fig. 9). By establish the new grooves, pressure was distributed in a more uniform manner.

The final design (Fig. 10) showed promising results compared to first one The pressure on the oil film was lesser than 10.0 MPa, which was the initially expected pressure. The placement of the inlets and holes ensures a wide range of support for the shaft without any significant reduction in pressure.
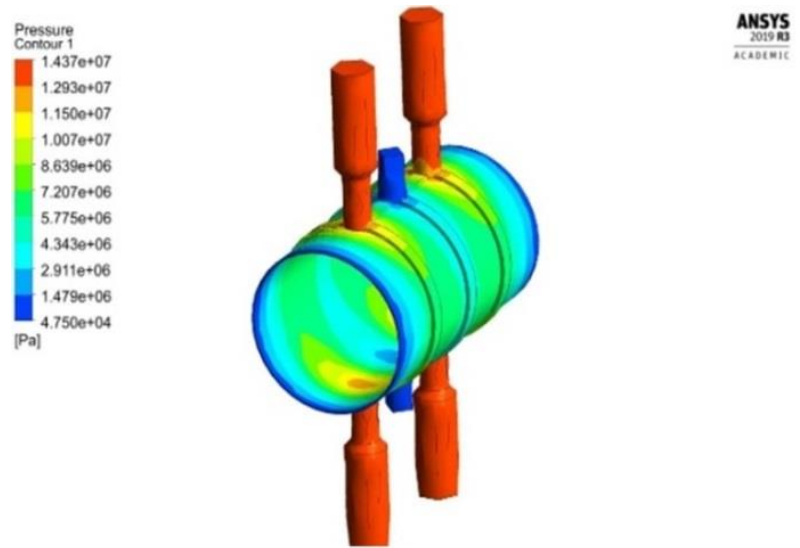

Fig. 10. Pressure distribution inside oil film 4

By placing the holes in between the inlets, more oil is removed and thus decreasing the pressure at the edges of the inlet. It was decide that this oil film design to be used for design of the actual journal bearing. There are here (Fig. 11) the diagram for the pressure formed in each oil film design. This is showing how each design affected the pressure, but the graph is for a soft visual comparison since a lot of design changes were experimented between different stages to verify the effectiveness.

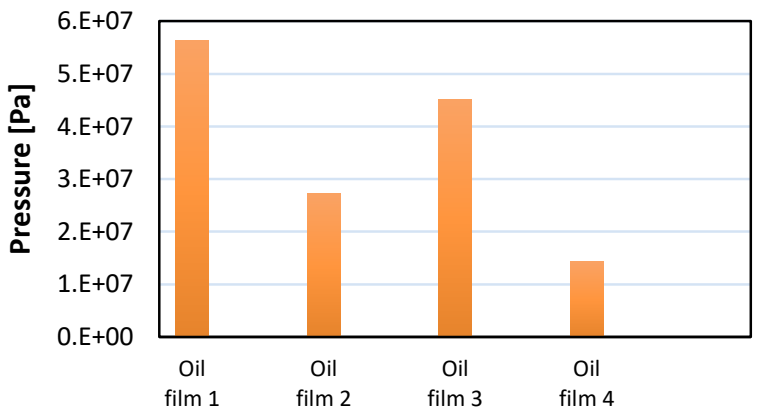

Fig. 11. Maximum pressure exerted by all the oil films

\subsection{Babbitt analysis}

The babbitt with $1 \mathrm{~mm}$ thickness was analysed using static structural analysis by applying the pressure exerted by the desired oil film. The result shows that, the highest pressure noted is near the inlet to the Babbitt (Fig. 12). The animation of the expansion due to the pressure shows, the babbitt expands at faster and higher rate near the inlet of the babbitt. This is due to pressure exerted at the inlet end was high in the oil film analysis. The holes in the babbitt design decreases the deformation at that point by a large value. 


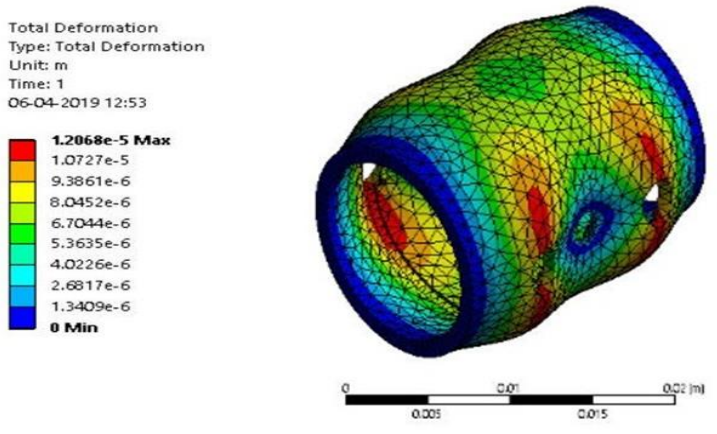

Fig. 12. Deformed babbitt 1 under pressure from oil film

In the $0.35 \mathrm{~mm}$ (Babbitt 2 - Fig. 13), the result showed a large difference in how the circumference, which is perpendicular to the inlet, deforms due to the pressure. This surface does not undergo a deformation compared to the other locations. The amount of deformation near the holes also increases which is a noted pattern as the thickness decreases. Since the material is a metallic, the stress-strain graph shows us that there can be an elastic deformation which changes to plastic after a certain value. This is noted here, the material deformation is easier near the inlet, thus it continues to deform to relieve the increase in pressure.

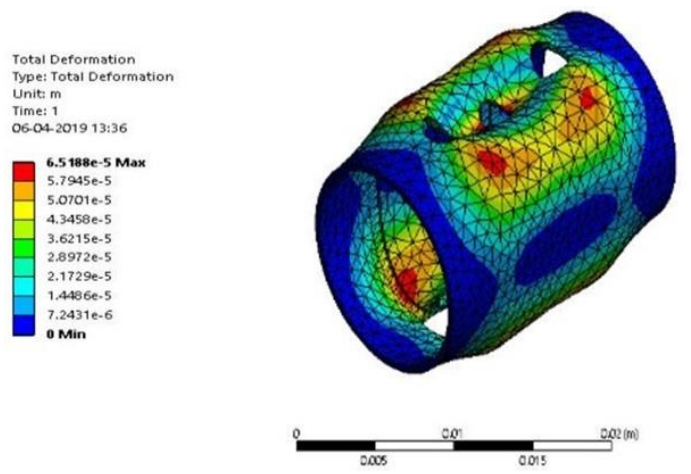

Fig. 13. Deformed babbitt 2 under pressure from oil film

The below table shows a comparison between the babbitts in mechanical properties.

Table 1. Comparison of the results for each Babbitt

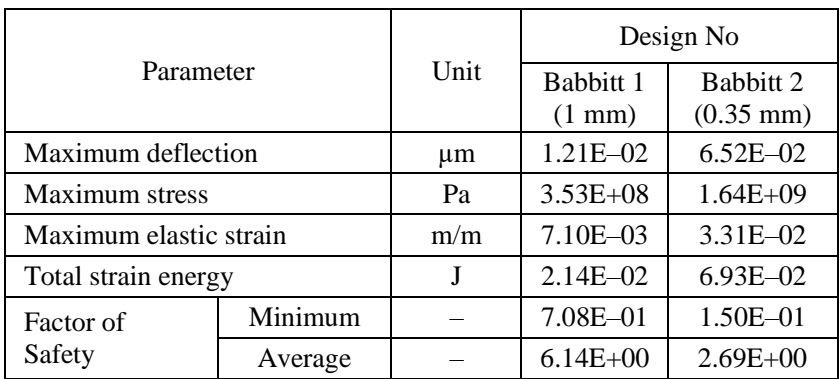

\subsection{Full bearing analysis}

The bearing with $1 \mathrm{~mm}$ babbitt is seen considerable improvements in deformation due to support provided by the steel backing. The babbitt is deforming in a uniform manner starting from the inlet to the periphery. The maximum stress developed also decreased by 10 times compared to just the babbitt supporting the pressure. The other parame- ter were also decreased by a considerable value except Factor of Safety (FoS). The average FOS value as seen in the Table 2 is a very good value which reinforce the safety factor of the bearing under operation. The maximum deformation is seen on the corner edge of the grooves near the inlet of the oil supply, since the stress concentration is more due to sharp edges present at those points.

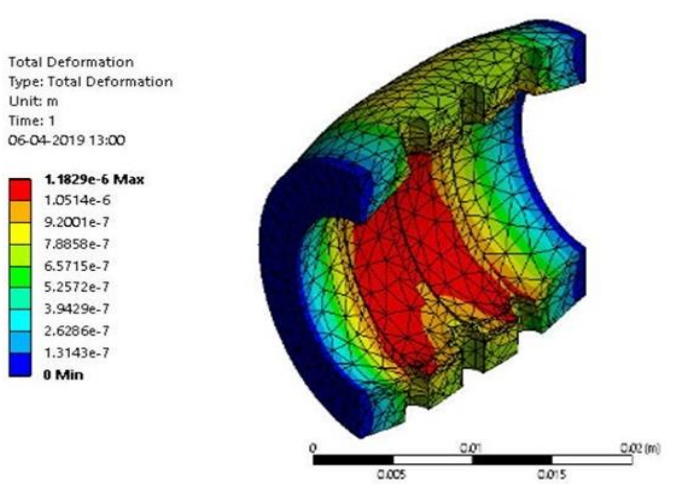

Fig. 14. Deformed bearing 1 under pressure from oil film

While analysing the bearing with $0.35 \mathrm{~mm}$ babbitt, the deflection further decreased in value, which means that as the thickness of the babbitt is decreased, the bearing properties are improved. Since the deflection was tending to decrease, we can see a relation which affects the strain energy acting on the bearing. The FOS value and the stress developed are closely related, thus the stress developed still remains the same.

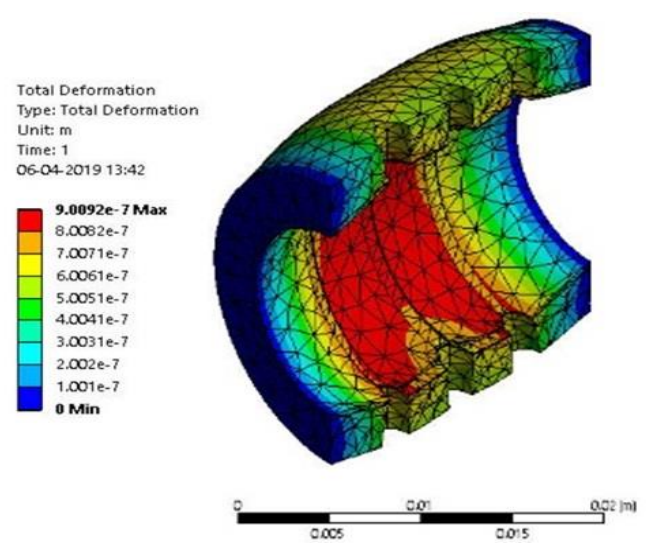

Fig. 15. Deformed bearing 2 under pressure from oil film

The table below shows a comparison of the bearings with their corresponding mechanical properties.

Table 2. Comparison of the results for each bearing

\begin{tabular}{|c|c|c|c|c|}
\hline \multirow{2}{*}{\multicolumn{2}{|c|}{ Parameter }} & \multirow[b]{2}{*}{ Unit } & \multicolumn{2}{|c|}{ Design No } \\
\hline & & & $\begin{array}{c}\text { Bearing } 1 \\
(1 \mathrm{~mm})\end{array}$ & $\begin{array}{l}\text { Bearing } 2 \\
(0.35 \mathrm{~mm})\end{array}$ \\
\hline \multicolumn{2}{|c|}{ Maximum deflection } & $\mu \mathrm{m}$ & $1.218-02$ & $9.00 \mathrm{E}-03$ \\
\hline \multicolumn{2}{|l|}{ Maximum stress } & $\mathrm{Pa}$ & $6.24 \mathrm{E}+07$ & $5.85 \mathrm{E}+07$ \\
\hline \multicolumn{2}{|c|}{ Maximum elastic strain } & $\mathrm{m} / \mathrm{m}$ & $4.49 \mathrm{E}-04$ & $3.98 \mathrm{E}-04$ \\
\hline \multicolumn{2}{|c|}{ Total strain energy } & $\mathrm{J}$ & $2.62 \mathrm{E}-03$ & $2.00 \mathrm{E}-03$ \\
\hline \multirow{2}{*}{ Factor of Safety } & Minimum & - & $4.73 \mathrm{E}+00$ & $5.04 \mathrm{E}+00$ \\
\hline & average & - & $1.44 \mathrm{E}+01$ & $1.46 \mathrm{E}+01$ \\
\hline
\end{tabular}




\section{Summary}

It seems that the main objectives of the project which was to design a slide bearing, so that it can withstand the forces generated due to the increased length of the shaft in the turbocharger has been achieved. The paper introduces a series of modernization of the bearing structure, considering the most favorable oil pressure distribution. The study takes into account changes in thickness of the oil film, the number of grooves and their dimensions, the number of inlets and outlets and the length of the slide bearing. Simulation models were created using CATIA V5 and the analysis is performed using ANSYS 19.2. With the help of the oil film, the babbitt plate was designed. It was having a higher deformation near to the inlet due to the higher pressure which is formed. The grooves were producing sharp ends near the inlet which also increases the stress concentration. The irregularity in deformation of the babbitt is caused by the holes reducing the pressure in its zone. During the babbitt analysis, it was observed that as the thickness increased the babbitt showed better properties under the pressure acting on them.

The babbitt was supported by the steel backing and was analysed, which showed that the lesser the babbitt thickness the more better the journal bearings performance. This property can be explained by the transfer of stress from one material to the other. The stress transfer is high when the distance between the point of stress application and the location of the second material is less. As stress travels over a longer distance, the material absorbs the energy and deforms. This cause less energy to be transferred to the second material, and making too much stress allocation on the first material. Thus, after using the steel backing, the babbitt with $0.35 \mathrm{~mm}$ proved to show more Factor of Safety and less deformation compared to the other bearings.

The currently constructed bearings can withstand about 150 bar of pressure in the oil film without having a significant change in dimensions. From the two bearings that were designed according to the oil film required, it can conclude that the $0.35 \mathrm{~mm}$ thick babbitt bearing is better than $1 \mathrm{~mm}$. The length of the bearing can be increased to without compromising in the pressure exerted at different location by making changes to the oil film design. Removing the edges in the grooves can decrease the concentration of stress and increase the Factor of Safety. All of the mentioned above items directly affect to overall efficiency of the engine due to the fact that the energy necessary to overcome frictional resistance is reduced.

\section{Acknowledgments:}

This research was supported by using resources GEO3EM Energy, Ecology, Education co-financed by the European Regional Development Fund.

\section{Bibliography}

[1] ANSYS Fluent Tutorial Guide. Ansys Inc. 2017.

[2] BAINES, N.C. Fundamentals of Turbocharging. Concepts ETI, Inc. 0933283148, 2005.

[3] BOMPOS, D.A., NIKOLAKOPOULOS, P.G. Tribological design of a multistep journal bearing. Simulation Modelling Practice and Theory. 2016, 68, 18-32. https://doi.org/10.1016/j.simpat.2016.07.002

[4] CAMPO E.A. Plastic journal bearing design. The Complete Part Design Handbook, 2006, 335-376.

[5] CHEN, W.J. Rotordynamics and bearing design of turbochargers. Mechanical Systems and Signal Processing. 2012, 29, 77-89. https://doi.10.1016/j.ymssp.2011.07.025

[6] CHUEPENG, S., SAIPOM, S. Lubricant thermo-viscosity effects on turbocharger performance at low engine load. $A p$ plied Thermal Engineering. 2018, 139, 334-340. https://doi.org/10.1016/j.applthermaleng.2018.05.002

[7] CYPKO, E., KALDONSKI, T. Influence of lubricated sliding couple structural material type on generated potential difference value. Journal of KONES Powertrain and Transport. 2011, 18(1).

[8] DOWSON, D., TAYLOR, C.M., GODET, M. et al. Fluid film lubrication - Osborne Reynolds centenary. Proceedings of 13th Leeds-Lyon Symposium on Tribology. 1986, 11. University of Leeds, England.

[9] KALDONSKI, T. Fundamentals of analysing od tribological processes. WAT Publisher. Warsaw 2015 (in Polish).

[10] KOUTSOVASILIS, P., DRIOT, N., DAIXING, L. et al. Quantification of sub-synchronous vibrations for turbocharger rotors with full-floating ring bearings. Archive Applied Mechanics. 2015, 85(4), 481-502. https://doi.org/10.1007/s00419-014-0924-0

[11] LAWROWSKI, Z. Tribology. friction, wear and lubrication. PWN Publisher. Warsaw 1993 (in Polish).

[12] LI, C., WANG, Y., JIA, B. et al. Application of Miller cycle with turbocharger and ethanol to reduce $\mathrm{NO}_{\mathrm{x}}$ and particu- lates emissions from diesel engine - a numerical approach with model validations. Applied Thermal Engineering. 2019, 150, 904-911.

https://doi.org/10.1016/j.applthermaleng.2019.01.056

[13] MANSHOOR, B., JAAT, M., IZZUDDIN, Z. et al. CFD analysis of thin film lubricated journal bearing. Procedia Engineering. 2013, 68, 56-62.

https://doi.org/10.1016/j.proeng.2013.12.147

[14] NICHOLAS, J., ALLAIRE, P., LEWIS, D. Stiffness and damping coefficients for finite length step journal bearings. ASLE Transactions. 2008, 23(4), 353-362. https://doi.org/10.1080/05698198008982979

[15] ROMAGNOLI, A., MANIVANNAN, A., RAJOO, S. et al. A review of heat transfer in turbochargers. Renewable and Sustainable Energy Reviews. 2017, 79, 1442-1460. https://doi.org/10.1016/j.rser.2017.04.119

[16] ROY L., LAHA, S. Steady state and dynamic characteristics of axial grooved journal bearings. Tribology International. 2009, 42(5), 754-761,

https://doi.org/10.1016/j.triboint.2008.10.010

[17] SCOTT, R. Journal bearings and their lubrication. Machinery Lubrication. Publish by Noria. 2005, 7, https://www.machinerylubrication.com/Read/779/journalbearing-lubrication

[18] SCHWARZ, J.B., ANDREWS, D.N. Considerations for gas stand measurement of turbocharger performance. Proceedings 11th International Conference on Turbochargers and Turbocharging. 2014, 253-264. Institute of Mechanical Engineers, London.

[19] SEP, J., TOMCZEWSKI, L., GALDA, L. et al. The study on abrasive wear of grooved journal bearings. Wear. 2017, 376-377, 54-62. https://doi.org/10.1016/j.wear.2017.02.034

[20] SHAABAN, S., SEUME, J. Impact of turbocharger nonadiabatic operation on engine volumetric efficiency and tur- 
bo lag. International Journal of Rotating Machinery. 2011, 2012. https://doi.org/10.1155/2012/625453

[21] SJOBERG, E. Friction characterization of turbocharger bearings. Master of Science Thesis MMK. 2013, 149.

[22] STAHL, J., JACOBSON, B.O. Design function for hydrodynamics bearings. Proceedings of the Institution of $\mathrm{Me}$ chanical Engineers, Part J: Journal of Engineering Tribology. 2001, 215(5), 405-416.

https://doi.org/10.1243/1350650011543637

Prof. Zbigniew Sroka, DSc., DEng. - Faculty of Mechanical Engineering, Wroclaw University of Science and Technology.

e-mail: zbigniew.sroka@pwr.edu.pl
[23] SUMMER, F., GRÜN, F., OFFENBECHER, M. et al. Challenges of friction reduction of engine plain bearings - tackling the problem with novel bearing materials. Tribology International. 2018, 131, 238-250.

https://doi:10.1016/j.triboint.2018.10.042

[24] VANHAELST, R., KHEIR, A., CZAJKA, J. A systematic analysis of the friction losses on bearings of modern turbocharger. Combustion Engines. 2016, 164(1), 22-31. https://doi.org/10.19206/CE-116485

Srinath Prakash, MEng. - Graduate of Faculty of Mechanical Engineering, Wroclaw University of Science and Technology.

e-mail: srinath.p2@gmail.com

Radoslaw Wlostowski, MEng. - Faculty of Mechanical Engineering, Wroclaw University of Science and Technology.

e-mail: radoslaw.wlostowski@pwr.edu.pl 